\title{
PROGNOZOWANIE W RAMACH BAYESOWSKICH MODELI VEC
}

\begin{abstract}
$\mathrm{Z}$ a ry s t r e ś c i. Wśród obserwowanych makroekonomicznych szeregów czasowych większość może być traktowana jako realizacja kowariancyjnie niestacjonarnych procesów stochastycznych. Wprowadzenie idei kointegracji umożliwiło poprawne, zarówno od strony statystycznej jaki i ekonomicznej, modelowanie takich szeregów. Celem niniejszego opracowania jest wykorzystanie metodologii bayesowskiej do prognozowania w ramach modelu VEC przyszłych wartości wektora obserwacji. Prognoza ta zostanie poprzedzona wyborem najbardziej prawdopodobnych specyfikacji z grupy modeli, które mogą się różnić długością opóźnienia w procesie VAR, rodzajem trendu deterministycznego, ilością relacji kointegrujących oraz liczbą i rodzajem dodatkowych restrykcji nakładanych na przestrzeń kointegrującą i/lub przestrzeń współczynników dostosowań. Wykorzystanie techniki bayesowskiego łączenia wiedzy pozwoli na otrzymanie prognozy punktowej oraz oszacowanie jej niepewności, która będzie odzwierciedlała nie tylko niepewność związaną z przyszłymi wartościami procesu i parametrów modelu, ale również z jego specyfikacją.
\end{abstract}

$\mathrm{S} \nmid$ o w a k 1 u c z o w e: kointegracja, wnioskowanie bayesowskie, prognozowanie, bayesowskie łączenie wiedzy.

\section{WSTĘP}

Wśród obserwowanych makroekonomicznych szeregów czasowych większość może być traktowana jako realizacja kowariancyjnie niestacjonarnych procesów stochastycznych. Wprowadzenie idei kointegracji (zob. np. Engle, Granger, 1987; Johansen, 1996) umożliwiło poprawne, zarówno od strony statystycznej jaki i ekonomicznej, modelowanie takich szeregów. Z twierdzenie Grangera o reprezentacji wynika, że każdy wielowymiarowy proces skointegrowany można przedstawić w postaci mechanizmu korekty błędu. Jedną z głównych zalet makroekonomicznych modeli z mechanizmem korekty błędu jest wyraźne oddzielenie zależności krótkookresowych od długookresowych, zwykle popartych teorią ekonomii i będących głównym celem analizy. Powszechnie znanym problemem pojawiającym się $\mathrm{w}$ analizie kointegracji jest 
nieidentyfikowalność parametrów wektorowego modelu z mechanizmem korekty błędu (VEC). Bezpośrednia interpretacja parametrów oszacowanych wektorów kointegrujących w przypadku, gdy rząd kointegracji jest większy niż jeden, jest zatem niemożliwa. Oszacowanie parametrów modelu z mechanizmem korekty błędu powinno być więc wstępem do dalszej analizy badanego zjawiska ekonomicznego, takiej na przykład jak prognoza, dekompozycja wariancji, czy też analiza reakcji wybranej zmiennej na zakłócenia zmiennych z sytemu.

Celem niniejszego opracowania jest wykorzystanie metodologii bayesowskiej do prognozowania, w ramach modelu VEC, przyszłych wartości wektora obserwacji. Prognoza ta zostanie poprzedzona wyborem najbardziej prawdopodobnych specyfikacji z grupy modeli, które mogą się różnić długością opóźnienia w procesie VAR, rodzajem trendu deterministycznego, ilością relacji kointegrujących oraz liczbą i rodzajem dodatkowych restrykcji nakładanych na przestrzeń kointegrująca i/lub przestrzeń współczynników dostosowań. Wykorzystanie techniki bayesowskiego łączenia wiedzy pozwoli na otrzymanie prognozy punktowej oraz oszacowanie jej niepewności, która będzie odzwierciedlała nie tylko niepewność związaną z przyszłymi wartościami procesu i parametrów modelu, ale również z jego specyfikacją.

Przedstawione metody zostaną zilustrowane prognozą inflacji oraz stopy bezrobocia dla gospodarki polskiej.

\section{BAYESOWSKI WEKTOROWY MODEL Z MECHANIZMEM KOREKTY BŁĘDU}

Rozważmy $n$-wymiarowy proces skointegrowany $\left\{\mathbf{x}_{\mathbf{t}}\right\}$, gdzie $t=1,2, \ldots, T$ oraz przedstawmy go w postaci modelu $\mathrm{z}$ mechanizmem korekty błędu:

$$
\begin{aligned}
\Delta \mathbf{x}_{t} & =\boldsymbol{\alpha}\left(\boldsymbol{\beta}^{+}{ }^{\prime} \mathbf{x}_{t-1}+\varphi_{1}^{\prime} \mathbf{d}_{1 t}\right)+\boldsymbol{\Gamma}_{0} \boldsymbol{\omega}_{t}+\sum_{i=1}^{k-1} \Gamma_{i} \Delta \mathbf{x}_{t-i}+\varphi_{2} \mathbf{d}_{t 2}+\boldsymbol{\varepsilon}_{t}= \\
& =\boldsymbol{\alpha} \boldsymbol{\beta}^{\prime} \mathbf{z}_{1 t}+\boldsymbol{\Gamma}^{\prime} \mathbf{z}_{2 t}+\boldsymbol{\varepsilon}_{t}, \quad t=1,2, \ldots, T,
\end{aligned}
$$

Dla uproszczenia notacji, zapiszmy model (1) w postaci macierzowej:

$$
\mathbf{Z}_{0}=\Delta \mathbf{X}=\mathbf{Z}_{1} \boldsymbol{\beta} \boldsymbol{\alpha}^{\prime}+\mathbf{Z}_{2} \boldsymbol{\Gamma}+\mathbf{E}=\mathbf{Z}_{1} \boldsymbol{\Pi}^{\prime}+\mathbf{Z}_{2} \boldsymbol{\Gamma}+\mathbf{E},
$$

gdzie $\mathbf{Z}_{0}=\left(\Delta \mathbf{x}_{1}, \Delta \mathbf{x}_{2}, \ldots, \Delta \mathbf{x}_{T}\right)^{\prime}, \mathbf{Z}_{1}=\left(\mathbf{z}_{11}, \mathbf{z}_{12}, \ldots, \mathbf{z}_{1 T}\right)^{\prime}, \mathbf{z}_{1 t}{ }^{\prime}=\left(\mathbf{x}_{t-1}{ }^{\prime}, \mathbf{d}_{1 t}{ }^{\prime}\right)$, $\mathbf{Z}_{2}=\left(\mathbf{z}_{21}, \mathbf{z}_{22}, \ldots, \mathbf{z}_{2 T}\right)^{\prime}, \mathbf{z}_{2 t}{ }^{\prime}=\left(\omega_{t}^{\prime} \Delta \mathbf{x}_{t-1}{ }^{\prime}, \Delta \mathbf{x}_{t-2}{ }^{\prime}, \ldots, \Delta \mathbf{x}_{t-k+1}{ }^{\prime}, \mathbf{d}_{2 t}{ }^{\prime}\right), \boldsymbol{\beta}=\left(\boldsymbol{\beta}^{+{ }^{\prime}} \boldsymbol{\varphi}_{1}{ }^{\prime}\right)^{\prime}$, $\Gamma=\left(\Gamma_{0}, \Gamma_{1}, \Gamma_{2}, \ldots, \Gamma_{k-1}, \varphi_{2}\right)^{\prime}, \mathrm{E}=\left(\boldsymbol{\varepsilon}_{1}, \boldsymbol{\varepsilon}_{2}, \ldots, \boldsymbol{\varepsilon}_{T}\right)^{\prime}, \boldsymbol{\varepsilon}_{t} \sim i i N^{n}(0, \boldsymbol{\Sigma}), t=1,2, \ldots, T$. Poprzez macierze $\mathbf{d}_{1 t}, \mathbf{d}_{1 t}$ możemy wprowadzić do modelu trendy deterministyczne, macierz $\boldsymbol{\omega}_{t}$ grupuje pozostałe zmienne nielosowe, macierz $\boldsymbol{\alpha}$ wymiaru $n \times r$ zawiera współczynniki dostosowań, $\boldsymbol{\beta}$ wymiaru $m \times r$ jest macierzą wektorów kointegrujących; $m \geq n$ oraz $m=n$, gdy w relacjach kointegrujących nie ma składowych deterministycznych. Macierze $\alpha$ oraz $\beta$ mają rząd równy $r$, gdzie $0 \leq r \leq n$. 
Dekompozycja macierzy $\Pi$ na iloczyn dwóch macierzy, $\alpha$ oraz $\beta$, o pełnym rzędzie kolumnowym $r$, równym liczbie relacji kointegrujących, jest dekompozycją tradycyjna, wynikającą z przypisywanej im interpretacji. Wadą tej dekompozycji jest niejednoznaczność, co oznacz, że dla dowolnej nieosobliwej macierzy $\mathbf{C}$ stopnia $r$ macierze $\Pi=\alpha \beta^{\prime}$ oraz $\Pi=\alpha \mathbf{C C}^{-1} \beta^{\prime}$ sa obserwacyjnie równoważne. Inaczej mówiąc, $w$ danych zawarta jest jedynie informacja o przestrzeni kointegrującej będącej elementem rozmaitości Grassmanna $\left(G_{r, m-r}\right)$, która jest zbiorem $r$-wymiarowych podprzestrzeni $\mathrm{R}^{m}$.

W niniejszej pracy wykorzystamy bayesowski model VEC zaproponowany przez Strachana i Indera (2004), w którym, w oparciu o pracę Jamesa (1954), do wyprowadzenia rozkładu a priori dla przestrzeni kointegrującej wykorzystano zależność pomiędzy rozmaitością Grassmanna i rozmaitością Stiefela $\left(V_{r, m}\right)$, będącą zbiorem $r$ - ram (ang. $r$-frames), tj. zbiorów złożonych z $r$ ortonormalnych wektorów z $\mathrm{R}^{m}$. Ograniczenie normy wektorów kointegrujących do jedności oraz ustalenie ich orientacji $\mathrm{w}$ przestrzeni kointegrującej nie utrudnia wnioskowania o tejże przestrzeni, ułatwia natomiast wyprowadzenie rozkładu a priori dla przestrzeni kointegrującej. Jednostajny rozkład na rozmaitości Stiefela prowadzi do jednostajnego rozkładu na rozmaitości Grassmanna. Obydwie rozważane rozmaitości są zwarte, czyli rozkłady jednostajne są właściwe. Czynniki Bayesa użyte do porównywania modeli, przy założeniu braku informacji a priori o przestrzeni kointegrującej, są więc dobrze zdefiniowane. Strachan i Inder (2004), wykorzystując klasę rozkładów $M A C G$ wprowadzoną przez Chikuse w 1990r. (ang. matrix angular central Gaussian distributions) definiuja również informacyjne rozkłady a priori, a tym samym prezentują sposób na wprowadzenie do modelu wstępnej wiedzy na temat estymowanych relacji kointegrujących.

Koop, León-González, Strachan (2007) zaproponowali, dla tej grupy modeli, algorytm uzyskania próby z rozkładu a posteriori oparty na próbniku Gibbsa. $\mathrm{W}$ algorytmie tym korzystamy z niejednoznaczności dekompozycji macierzy П: $\boldsymbol{\Pi}=\widetilde{\boldsymbol{\alpha}} \widetilde{\boldsymbol{\beta}}^{\prime}=\widetilde{\boldsymbol{\alpha}} \mathbf{D} \mathbf{D}^{-1} \widetilde{\boldsymbol{\beta}}^{\prime}=(\widetilde{\boldsymbol{\alpha}} \mathbf{D})\left(\widetilde{\boldsymbol{\beta}} \mathbf{D}^{-1}\right)^{\prime} \equiv \boldsymbol{\alpha} \boldsymbol{\beta}^{\prime}$, gdzie $\mathbf{D}$ jest dodatnio określoną macierzą wymiaru $r \times r$. Algorytm polega na przełączaniu się pomiędzy tymi parametryzacjami oraz wymaga losowania $\mathrm{z}$ rozkładów macierzowego normalnego i odwróconego Wisharta.

\section{BAYESOWSKIE PORÓWNYWANIE KONKURENCYJNYCH MODELI I ŁĄCZENIE WIEDZY}

Metodologia bayesowska dostarcza również narzędzia wyboru adekwatnego modelu z grupy modeli, które mogą różnić się kilkoma cechami jednocześnie. Wybór modelu odbywa się na podstawie prawdopodobieństwa a posteriori obliczonego dla każdego modelu z kompletnego zbioru parami wykluczających 
się modeli opisujących badane zjawisko (Osiewalski, Steel, 1993; Osiewalski, 2001; Pajor, 2003).

Rozważmy grupę bayesowskich modeli VEC indeksowanych wektorem $\xi$ : $\left\{M_{\xi}, \xi=(k, r, d, o, e) \in \Xi\right\}:$

$$
M_{\xi}: p_{\xi}\left(X, \theta_{(\xi)}\right)=p_{\xi}\left(\theta_{(\xi)}\right) p_{\xi}\left(X \mid \theta_{(\xi)}\right), \quad \xi \in \Xi,
$$

gdzie $X$ oznacza dane, $\theta_{(\xi)} \in \Xi$ jest wektorem parametrów modelu $M_{\xi}$, a $p_{\xi}\left(\theta_{(\xi)}\right)$ oznacza rozkład a priori przyjęty dla parametrów modelu $M_{\xi}$. Składowe wektora $\xi$ opisują cechy, którymi mogą różnić się modele VEC: $k$ wyznacza długość opóźnienia w dynamice krótkookresowej, $r$ - liczbę relacji kointegrujących, $d$ - rodzaj trendu, $o$ - dodatkowe restrykcje nałożone na przestrzeń kointegrująca, $e$ - formę egzogeniczności wybranych zmiennych.

Wykorzystując twierdzenia Bayesa możemy obliczyć prawdopodobieństwa a posteriori według następującego wzoru:

$$
p\left(M_{\xi} \mid X\right)=\frac{p\left(M_{\xi}\right) p\left(X \mid M_{\xi}\right)}{\sum_{\zeta \in \Xi} p\left(M_{\varsigma}\right) p\left(X \mid M_{\varsigma}\right)}, \quad \xi \in \Xi,
$$

gdzie $p\left(X \mid M_{\xi}\right)$ jest brzegową gęstością wektora obserwacji w modelu $M_{\xi}, \mathrm{tj}$

$$
p\left(X \mid M_{\xi}\right)=\int_{\Theta_{(\xi)}} p_{\xi}\left(X \mid \theta_{(\xi)}\right) p_{\xi}\left(\theta_{(\xi)}\right) d \theta_{(\xi)}, \quad \xi \in \Xi .
$$

Analityczne obliczenie całek danych wzorem (5) jest zazwyczaj bardzo skomplikowane lub wręcz niemożliwe, dlatego też do ich wyznaczenia stosuje się metody numeryczne (zob. np. Newton, Raftery, 1994; Kass, Raftery, 1995; Chib, 1995; Gamerman, 1997) lub aproksymacje, np. aproksymację Laplace'a (zob. np. Kass, Raftery, 1995 oraz Strachan, Inder, 2004 dla modelu VEC). Mając próbę wylosowaną według rozkładu a posteriori dla parametrów modelu $M_{\xi}$ wartość brzegowej gęstości wektora obserwacji można na przykład przybliżać średnią harmoniczną z wartości funkcji wiarygodności (Newton, Raftery, 1994; Kass, Raftery, 1995):

$$
\hat{p}\left(X \mid M_{\xi}\right)=\left(\frac{1}{M} \sum_{m=1}^{M} \frac{1}{p_{\xi}\left(X \mid \theta_{(\xi) i}\right)}\right)^{-1} .
$$

Wyznaczone prawdopodobieństwa a posteriori można wykorzystać w dalszej analizie, stosując metodę bayesowskiego łączenia wiedzy, dzięki czemu otrzymane wnioski nie będą opierały się na jednym wybranym modelu, ale będą odzwierciedlały również niepewność związaną z jego specyfikacją (zob. np. Osiewalski, 2001).

Niech $\psi$ będzie podzbiorem parametrów wspólnych dla modeli w rozważanej klasie $\left\{M_{\xi}, \xi \in \Xi\right\}$, wówczas gęstość a posteriori $\psi$ dana jest równaniem: 


$$
p(\psi \mid X)=\sum_{\xi \in \Xi} p\left(\psi \mid X, M_{\xi}\right) p\left(M_{\xi} \mid X\right),
$$

gdzie $p\left(M_{\xi} \mid X\right)$ jest prawdopodobieństwem a posteriori modelu $M_{\xi}$, a $p\left(\psi \mid X, M_{\xi}\right)$ gęstością a posteriori $\psi \mathrm{w}$ modelu $M_{\xi}$.

W niniejszym opracowaniu metoda bayesowskiego łączenia wiedzy zostanie wykorzystana do wyznaczenia prognozy wektora przyszłych obserwacji.

\section{PROGNOZOWANIE W RAMACH BAYESOWSKIEGO MODELU VEC}

Bayesowska predykcja oparta jest na rozkładzie predyktywnym, tj. na warunkowym względem obserwacji rozkładzie przyszłych wartości analizowanego procesu. Oznaczmy wektor prognozowanych wartości przez:

$$
\widetilde{X}=\left(x_{T+1}, x_{T+2}, \ldots, x_{T+h}\right)^{\prime},
$$

gdzie $h$ jest horyzontem prognozy. Warunkowy, względem zaobserwowanych wartości $X$, rozkład predyktywny otrzymujemy uśredniając, po przestrzeni parametrów, tzw. próbkową gęstość predyktywną $p(\tilde{X} \mid \theta, X)$ z wykorzystaniem gęstości rozkładu a posteriori dla parametrów modelu jako funkcji wagowej (Osiewalski, 2001; Zellner, 1971):

$$
p(\widetilde{X} \mid X)=\int_{\Theta} p(\widetilde{X}, \theta \mid X) d \theta=\int_{\Theta} p(\widetilde{X} \mid \theta, X) p(\theta \mid X) d \theta .
$$

Tak wyznaczony rozkład predyktywny uwzględnia niepewność związaną zarówno z wartościami prognozowanymi, jak i również z wartością parametrów.

Dodatkowo, wykorzystując technikę bayesowskiego łączenia wiedzy, dla wyznaczenia prognozy, możemy rozważyć nie jeden model bayesowski, ale ich zbiór $\left\{M_{\xi}: \xi \in \Xi\right\}$ :

$$
\begin{aligned}
p(\tilde{X} \mid X) & =\sum_{\xi \in \Xi} p\left(M_{\xi} \mid X\right) p\left(\tilde{X} \mid X, M_{\xi}\right)= \\
& =\sum_{\xi \in \Xi} p\left(M_{\xi} \mid X\right) \int_{\Theta_{\xi}} p\left(\widetilde{X} \mid \theta_{\xi}, X\right) p\left(\theta_{\xi} \mid X\right) d \theta_{\xi} .
\end{aligned}
$$

W wyniku łączenia wiedzy otrzymujemy zatem jeden rozkład predyktywny będący średnią ważoną rozkładów predyktywny $\mathrm{w}$ rozważanych modelach $\mathrm{z}$ wagami równymi prawdopodobieństwom a posteriori tych modeli.

Otrzymany rozkład predyktywny prezentuje całą wiedzę badacza na temat przyszłych wartości badanego procesu, warunkową względem jego zrealizowanych wartości. Chcąc podsumować te wiedzę możemy, wykorzystując rozkład predyktywny, wyznaczyć prognozę punktową oraz podać ocenę jej niepewności. Prognoza punktowa jest rozwiązaniem następującego problemu (Zellner, 1971): 


$$
\min _{\tilde{X}} \int_{R \tilde{X}} L(\tilde{X}, \hat{X}) p(\tilde{X} \mid X) d \widetilde{X}
$$

gdzie $L(\tilde{X}, \hat{X})$ oznacza przyjętą funkcję starty, a $\hat{X}$ prognozę punktową.

Wartość oczekiwana rozkładu predyktywnego jest optymalną prognozą punktowa, gdy jako funkcję straty przyjmiemy formę kwadratową (tj. kwadratową funkcję starty). Wartość oczekiwaną oraz wariancję rozkładu predyktywnego danego wzorem (9) można wyznaczyć znając wartości oczekiwane oraz wariancje rozkładów predyktywnych rozważanych modeli (zob. np. Villani, 2001):

$$
\begin{aligned}
& E(\tilde{X} \mid X)=\sum_{\xi \in \Xi} p\left(M_{\xi} \mid X\right) E\left(\tilde{X} \mid X, M_{\xi}\right), \\
& \left.V(\tilde{X} \mid X)=\sum_{\xi \in \Xi} p\left(M_{\xi} \mid X\right) V\left(\tilde{X} \mid X, M_{\xi}\right)+\sum_{\xi \in \Xi} p\left(M_{\xi} \mid X\right) E\left(\tilde{X} \mid X, M_{\xi}\right)-E(\tilde{X} \mid X)\right]^{2},
\end{aligned}
$$

które można oszacować wykorzystując próby wylosowane według rozkładów predyktywnych dla tych modeli.

\section{WYNIKI EMPIRYCZNE}

Przedstawione procedury wnioskowania bayesowskiego $\mathrm{w}$ ramach modelu VEC zostaną zilustrowane prognozą inflacji oraz stopy bezrobocia dla gospodarki polskiej. Prognoza została poprzedzona analizą spirali płacowo - cenowej z wykorzystaniem obserwacji kwartalnych z lat 1995-2007 dla pięciu szeregów czasowych: logarytmu płac przeciętnych z sektora przedsiębiorst $(w)$, logarytmu indeksu cen konsumpcyjnych $(p)$, logarytmu wydajności pracy $(z)$, logarytmu indeksu cen importu $(m)$, stopy bezrobocia (w procentach, $U$ ).

Rozważono zbiór modeli różniących się długością opóźnienia w modelu VAR, $k \in\{1,2,3,4\}$, rodzajem trendu, $d \in\{1,2,3,4,5\}$, rzędem macierzy mnożników długookresowych $\Pi, r \in\{0,1,2,3,4,5\}$ oraz restrykcjami nałożonymi na przestrzeń wektorów kointegrujących, $o \in\{0,1\}$, lub/i przestrzeń współczynników dostosowań, $e \in\{0,1\}$. Rodzaje trendu, a także rodzaje restrykcji, odpowiadające kolejnym wartościom indeksów $d$, o, oraz $e$ prezentuje tabela 1 .

Po uwzględnieniu wszystkich kombinacji rozważanych cech, pozostawieniu po jednym przedstawicielu ze zbioru modeli równoważnych (np. dla $r=0, d=2$ oraz $r=0, d=3$ otrzymujemy modele obserwacyjnie równoważne) i wykluczeniu kombinacji niemożliwych (np. $r=0, o \neq 0$ ) otrzymujemy 344 modele, dla których przyjęto równe prawdopodobieństwa a priori, obliczone według schematu zaproponowanego przez Strachana i van Dijka (2007). Ze względu na sezonowość analizowanych danych do każdego modelu wprowadzono zmienne sezonowe. 
Tabela 1. Rodzaje trendu i restrykcji odpowiadające kolejnym wartościom indeksów $d$, $o$, oraz $e$

\begin{tabular}{|c|l|}
\hline$d=1$ & $\begin{array}{l}\varphi_{1} d_{1 t}=\mu_{1}+\delta_{1} t, \varphi_{2} d_{2 t}=\mu_{2}+\delta_{2} t, \text { w relacjach kointegrujących jest trend liniowy, proces } x_{t} \text { ma } \\
\text { trend kwadratowy }\end{array}$ \\
\hline$d=2$ & $\begin{array}{l}\varphi_{1} d_{1 t}=\mu_{1}+\delta_{1} t, \varphi_{2} d_{2 t}=\mu_{2}, \text { w relacjach kointegrujacych jest trend liniowy, proces } x_{t} \text { ma trend } \\
\text { liniowy }\end{array}$ \\
\hline$d=3$ & $\begin{array}{l}\varphi_{1} d_{1 t}=\mu_{1}, \varphi_{2} d_{2 t}=\mu_{2}, \text { relacje kointegrujacej mają niezerową wartość oczekiwana, proces } x_{t} \\
\text { ma trend liniowy }\end{array}$ \\
\hline$d=4$ & $\begin{array}{l}\varphi_{1} d_{1 t}=\mu_{1}, \varphi_{2} d_{2 t}=0, \text { relacje kointegrującej mają niezerową wartość oczekiwana, proces } x_{t} \text { nie } \\
\text { ma trendu deterministycznego }\end{array}$ \\
\hline$d=5$ & $\begin{array}{l}\varphi_{1} d_{1 t}=0, \varphi_{2} d_{2 t}=0, \text { relacje kointegrującej mają zerową wartość oczekiwana, proces } x_{t} \text { nie ma } \\
\text { trendu deterministycznego }\end{array}$ \\
\hline $0=0$ & brak dodatkowych restrykcji dla przestrzeni kointegrującej \\
\hline $0=1$ & jednorodność w równaniu cen \\
\hline$e=0$ & brak dodatkowych restrykcji dla przestrzeni współczynników dostosowań \\
\hline$e=1$ & słaba egzogeniczność cen importu \\
\hline
\end{tabular}

Przyjęto następujące rozkłady a priori: $\beta \mid v \sim M A C G\left(I_{m}\right)$, czyli rozkład jednostajny na rozmaitości Grassmanna, $\widetilde{\alpha} \mid v, r, \Sigma \sim m N\left(0, v I_{r}, \Sigma\right), \Sigma \sim i W\left(I_{5}, 7\right)$, $\Gamma \mid \Sigma, h \sim m N\left(0, \Sigma, h I_{5(k-1)+l}\right), v \sim i G(2,3), h \sim i G(20,3), p\left(M_{\xi}\right)=0,003$.

Do uzyskania próby z rozkładu a posteriori wykorzystano schemat losowania Gibbsa zaproponowany przez Koopa, León-Gonzáleza i Strachana (2007).

Dokładna analiza modeli, które otrzymały najwyższe prawdopodobieństwo a posteriori prowadzi do wniosku, że badany szereg wielowymiarowyzintegrowany stopnia $2, X \sim \mathrm{I}(2)$, dlatego przed przystapieniem do prognozowania dokonano transformacji oryginalnych (nominalnych) zmiennych do realnych, tj. zastapiono płace nominalne realnymi $(w-p)$, indeks cen - inflacją $(\Delta p)$ oraz indeks cen importu różnicą $m-p$. Transformacja ta jest możliwa, ponieważ łączne prawdopodobieństwo a posteriori dla grupy modeli z restrykcją jednorodności w równaniu cen wynosi 0,564 . Wyniki bayesowskiego porównania modeli dla danych transformowanych zawiera tabela 2 .

Tabela 2. Modele o najwyższym prawdopodobieństwie a posteriori dla danych transformowanych

\begin{tabular}{|c|c|c|c|c|c|}
\hline $\mathrm{k}$ & $\mathrm{d}$ & $\mathrm{r}$ & $\mathrm{e}$ & $\mathrm{p}\left(\mathrm{M}_{(\mathrm{k}, \mathrm{d}, \mathrm{r}, \mathrm{o}, \mathrm{e})} \mid \mathrm{x}\right)$ & $\log _{10}\left(\hat{\mathrm{p}}\left(\mathrm{x} \mid \mathrm{M}_{(\mathrm{k}, \mathrm{d}, \mathrm{r}, 0, \mathrm{e}))}\right)\right.$ \\
\hline 2 & 4 & 1 & 1 & 0,460 & 57,073 \\
1 & 5 & 1 & 0 & 0,134 & 56,538 \\
2 & 5 & 1 & 0 & 0,078 & 56,303 \\
2 & 4 & 1 & 0 & 0,047 & 56,085 \\
1 & 5 & 0 & 0 & 0,036 & 55,967 \\
\hline
\end{tabular}

Tabela zawiera modele o prawdopodobieństwie a posteriori nie mniejszym niż 0,03 .

Źródło: obliczenia własne.

Wykorzystując, w grupie modeli o prawdopodobieństwie a posteriori nie niższym niż 0,03 , technikę bayesowskiego łączenia wiedzy dokonano prognozy inflacji oraz stopy bezrobocia na 12 kwartałów poza próbę, tj. na lata 
2008 - 2010. Wybrane histogramy tak otrzymanych brzegowych rozkładów predyktywnych prezentuje wykres 1 , natomiast $\mathrm{w}$ tabeli 3 zebrano wartości oczekiwane oraz odchylenia standardowe (w nawiasach) tych rozkładów.

Tabela 3. Wartości oczekiwane oraz odchylenia standardowe (w nawiasach) brzegowych rozkładów predyktywnych

\begin{tabular}{|c|c|c|c|c|}
\hline \multicolumn{5}{|c|}{$\Delta p$ : inflacja } \\
\hline & 1 & II & III & IV \\
\hline 2008 & $\begin{array}{c}0,0200 \\
(0,1520)\end{array}$ & $\begin{array}{c}0,0200 \\
(0,2241)\end{array}$ & $\begin{array}{c}0,0086 \\
(0,2844)\end{array}$ & $\begin{array}{c}0,0177 \\
(0,3364)\end{array}$ \\
\hline Wartości zrealizowane & 0,0149 & 0,0139 & 0,0020 & 0,0060 \\
\hline 2009 & $\begin{array}{c}0,0215 \\
(0,3887)\end{array}$ & $\begin{array}{c}0,0211 \\
(0,4373)\end{array}$ & $\begin{array}{c}0,0095 \\
(0,4822)\end{array}$ & $\begin{array}{c}0,0183 \\
(0,5245)\end{array}$ \\
\hline Wartości zrealizowane & 0,0119 & & & \\
\hline 2010 & $\begin{array}{c}0,0217 \\
(0,5681)\end{array}$ & $\begin{array}{c}0,0212 \\
(0,6098)\end{array}$ & $\begin{array}{c}0,0095 \\
(0,6497)\end{array}$ & $\begin{array}{c}0,0181 \\
(0,6879) \\
\end{array}$ \\
\hline \multicolumn{5}{|c|}{ U: stopa bezrobocia } \\
\hline & I & II & III & IV \\
\hline 2008 & $\begin{array}{c}11,53 \\
(0,517)\end{array}$ & $\begin{array}{c}10,43 \\
(0,964)\end{array}$ & $\begin{array}{c}10,17 \\
(1,436)\end{array}$ & $\begin{array}{c}10,54 \\
(1,922)\end{array}$ \\
\hline Wartości zrealizowane & 10,9 & 9,4 & 8,9 & 9,5 \\
\hline 2009 & $\begin{array}{c}11,04 \\
(2,435)\end{array}$ & $\begin{array}{c}10,22 \\
(2,947)\end{array}$ & $\begin{array}{c}10,17 \\
(3,451)\end{array}$ & $\begin{array}{c}10,72 \\
(3,944)\end{array}$ \\
\hline Wartości zrealizowane & 10,7 & 10,8 & & \\
\hline 2010 & $\begin{array}{c}11,33 \\
(4,434)\end{array}$ & $\begin{array}{c}10,60 \\
(4,913)\end{array}$ & $\begin{array}{c}10,61 \\
(5,376)\end{array}$ & $\begin{array}{c}11,18 \\
(5,822)\end{array}$ \\
\hline
\end{tabular}

Źródło: obliczenia własne.

Punktowa prognoza inflacji znacznie przewyższa wartości zrealizowane, jednak, z powodu dużego błędu ex ante, którym jest obarczona, wartości rzeczywiste mieszczą się w obszarze wysokiej gęstości prawdopodobieństwa rozkładów predyktywnych. Prognoza punktowa stopy bezrobocia na poziomie wartości oczekiwanej rozkładu predyktywnego również jest wyższa od zaobserwowanej, jednak i w tym przypadku wartości zrealizowane mieszczą się w obszarze $+/$ - dwóch odchyleń standardowych od prognozy punktowej.

\section{PODSUMOWANIE}

$\mathrm{W}$ niniejszej pracy zaprezentowano zalety bayesowskiego prognozowania w wektorowych modelach korekty błędu. Pokazano, że metodologia Bayesowska pozwala na formalne porównanie modeli różniących się kilkoma cechami jednocześnie, a wykorzystując technikę bayesowskiego łączenia wiedzy możemy otrzymać prognozę uwzględniającą niepewność związaną z tym wyborem. Wiedza na temat przyszłych wartości procesu prezentowana jest za pomocą rozkładu predyktywnego. Podsumowaniem tej wiedzy może być podanie momentów rozkładu. 


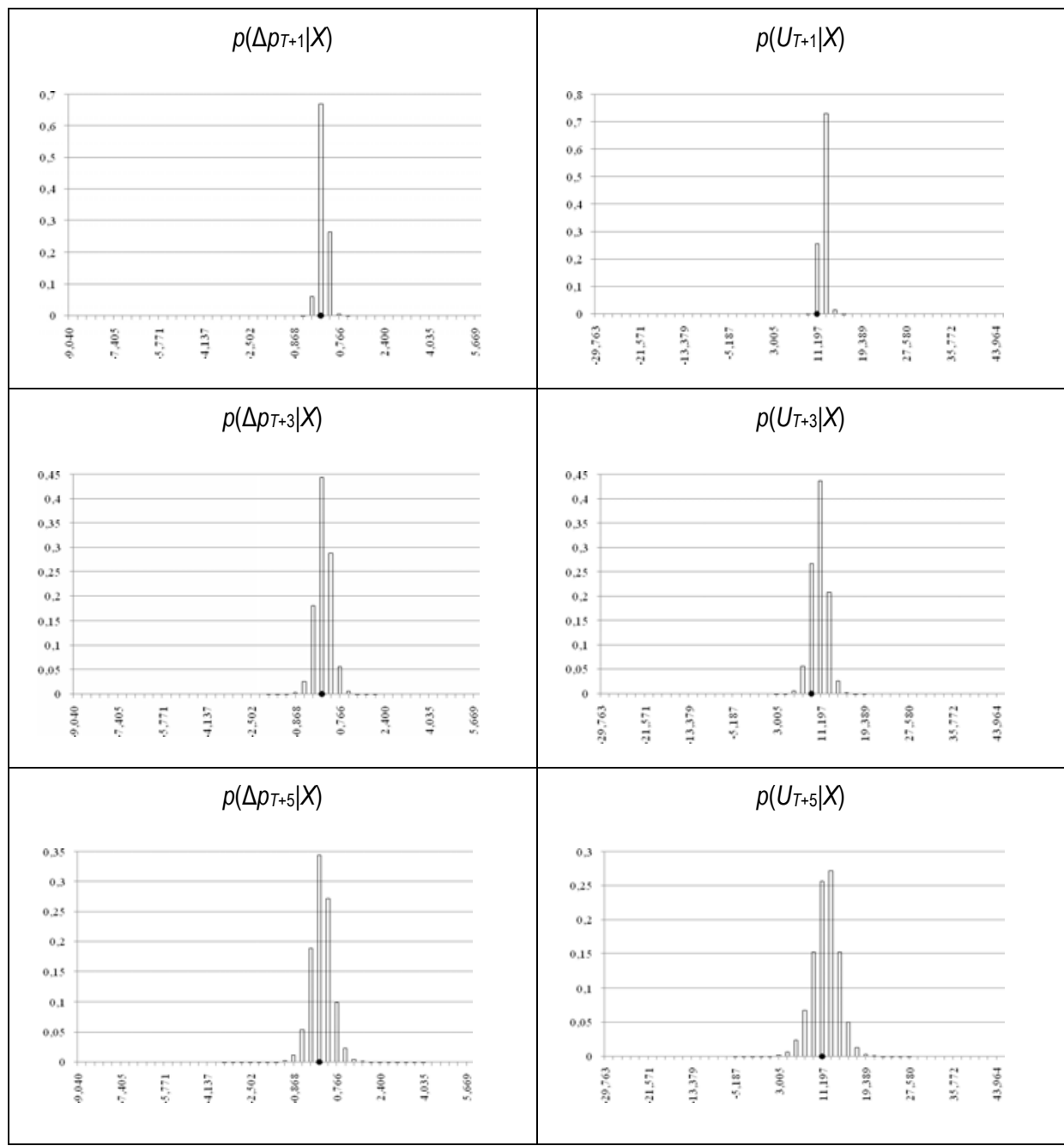

Wykres 1 . Histogramy wybranych brzegowych rozkładów predyktywnych po zastosowaniu techniki bayesowskiego łączenia wiedzy (czarnym punktem zaznaczono wartości zrealizowane)

Źródło: opracowanie własne.

\section{LITERATURA}

Chib S. (1995), Marginal likelihood from the Gibbs output, „Journal of the American Statistical Association", nr 90, 1313-1321.

Engle R.F., Granger C.W.J. (1997), Cointegration and error correction: representation, estimation and testing, ,Econometrica”, nr 55, 251-276.

Gamerman D. (1997), Marcov Chain Monte Carlo. Stochastic simulation for Bayesian inference, Chapman and Hall, London. 
Johansen S. (1996), Likelihood-based inference in cointegrated vector auto-regressive models, New York: Oxford University Press.

Kass R.E., Raftery A.E. (1995), Bayes factors, „Journal of the American Statistical Association” nr 90, 773-795.

Koop G., León-González R., Strachan R. (2007), Efficient posterior simulation for cointegrated models with priors on the cointegration space, Working Paper No. 05/13, University of Leicester, Department of Economics.

Lutkepohl, H. (2007), New Introduction to Multiple Time Series Analysis. Springer-Verlag, Berlin Heidelberg.

Newton M.A., Raftery A.E. (1994), Approximate Bayesian inference by the weighted likelihood bootstrap (with discussion), ,Journal of the Royal Statistical Society”, Ser. B nr 56, 3-48.

Osiewalski J. (2001), Ekonometria bayesowska w zastosowaniach, Wydawnictwo Akademii Ekonomicznej w Krakowie, Kraków.

Osiewalski J., Steel M. (1993), A Bayesian perspective on model selection (maszynopis), opublikowano w języku hiszpańskim: Una perspectiva bayesiana en selección de modelos, „Cuadernos Economicos", 55/3.

Pajor A. (2003), Procesy zmienności stochastycznej SV w bayesowskiej analizie finansowych szeregów czasowych, Wydawnictwo Akademii Ekonomicznej w Krakowie, Kraków.

Strachan R.W., Inder B. (2004), Bayesian analysis of the error correction model, „Journal of Econometrics", nr 123, 307-325.

Villani M. (2001), Bayesian prediction with cointegrated vector autoregressions, „International Journal of Forecasting", nr 17, 585-605.

Zellner A. (1971), An Introduction to Bayesian Inference in Econometrics. J. Wiley, New York.

\section{BAYESIAN PREDICTION IN THE VEC MODELS}

$\mathrm{A} \mathrm{b} \mathrm{s} \mathrm{tra} \mathrm{ct.} \mathrm{The} \mathrm{majority} \mathrm{of} \mathrm{the} \mathrm{observed} \mathrm{macroeconomic} \mathrm{time} \mathrm{series} \mathrm{may} \mathrm{contain} \mathrm{stochastic}$ trends or unit roots. After the introduction of the conception of the cointegration (which enables proper modelling of such time series) an enormous development of methods of its analysis can be observed in classical as well in Bayesian econometrics. The aim of this paper is to present a Bayesian approach to prediction in the framework of the VEC model. The presented methods will be applied to the forecast of the Polish inflation and the rate of unemployment preceded by the analysis of the price - wage mechanism.

K e y w o r d s: cointegration, Bayesian analysis, forecasting, Bayesian model averaging. 